\title{
Comprehensiveness Subcommittee B
}

National Cancer Institute

\section{Source}

National Cancer Institute. Comprehensiveness Subcommittee B. NCI Thesaurus. Code C19512.

An Initial Review Group that was terminated in June 1996. 